\title{
Experimental Investigation of the Effect of Micro- Silica and Zeolite on Repair Mortar of Concrete Pavements
}

\author{
Saeed Farzin ${ }^{\mathrm{a} *}$, Gholamali Shafabakhsh ${ }^{\mathrm{b}}$, Ehsan Teymouric, \\ Mohammad Reza Aeine Heydari ${ }^{\mathrm{d}}$, and Mana Motamedi ${ }^{\mathrm{e}}$ \\ Faculty of Civil Engineering, Semnan University, Semnan, I.R. of Iran \\ E-mail: asaeed.farzin@semnan.ac.ir (Corresponding author), bshafabakhsh@semnan.ac.ir, \\ cteymuri.e11@gmail.com,dmohamadhidary52@yahoo.com, ${ }^{\circ}$ mana.motamedi@gmail.com.
}

\begin{abstract}
In the recent years, by replacing a part of our country's asphalt pavements with concrete pavements, it is necessary to perform appropriate actions in order to preserve and repair destructions (due to executive weaknesses, loading and environmental conditions) during pavement lifetime. In order to increase mechanical properties and durability of repair mortars, micro-silica and zeolite were used as pozzolan, polypropylene fibers for controlling crack (due to fluctuations in concrete and temperature change) and the cement type 3 for obtaining high resistivity in short-term. In this study, 11mixing designs were investigated, and the composition of polypropylene fibers with micro-scale thickness with cement complements can be considered as the most optimal mixing design in $0.2 \%$ of fibers with $10 \%$ micro-silica and $15 \%$ zeolite in order to promote effective parameters of elasticity modulus, modulus of rupture and decrease of contraction in repair mortars of concrete pavements. By adding polypropylene fibers, the samples were not completely ruptured in the tension of primary strength that they showed. The samples containing $0.4 \%$ fibers with deformation from spherical state to elliptical state with splay value in rupture surface showed individual characteristic which caused minimizing rupture and crunch in the repaired area.
\end{abstract}

Keywords: Polypropylene fibers, micro-silica, zeolite, strong repair mortar, mechanical properties.

ENGINEERING JOURNAL Volume 21 Issue 2

Received 16 May 2016

Accepted 31 August 2016

Published 31 March 2017

Online at http://www.engj.org/

DOI:10.4186/ej.2017.21.2.213 


\section{Introduction}

Concrete pavements under structural and environmental loads tend to destruction and decrease of lifetime; therefore, they need structural materials with high operational and resisting properties for repair. The methods of depth and partial repairs are mostly used for repair and reinforcement of pavement and repair of cracks and the seams by filling and controlling with load transmission bars. The consistency of old and new material behavior are important in repair and reinforcement. The appropriate contact surface between fresh concrete and existing concrete can be created by roughing the surface of old concrete, using epoxy glue and grout before pouring concrete. This continuity causes the repaired element to act integrally not having weakness in the repaired section.

Repair materials should have appropriate operations for repair and should not be prone to destruction. The selection of used repair materials or concrete type must be carried out based on the existing time for blocking the line. In common repair operations, 360 to $460 \mathrm{~kg} / \mathrm{m}^{3}$ of the cement type one or three are usually used together with accelerator to make possible traffic passing after one to three days and in some cases, this duration decreases to 4 to $6 \mathrm{~h}$ using specific accelerators [1]. There are several kinds of common repair materials including different portland cement concretes, cement concrete of magnesium phosphate, cement concrete of calcium aluminate, epoxy mortar, polymeric concrete of methyl methacrylate, correcting cement polymer (latex) [1,2].

Loading causes bending and finally the creation of compressive and tensile stresses in pavement. The strength of concrete against tensile stresses induced by bending is called bending strength or rupture modulus of concrete. Since bending stresses approach the strength of concrete tensile limit faster than compressive stresses, the elasticity modulus is used together with the concrete rupture modulus in the designation of concrete pavements. Also, the contraction from losing water in concrete is an important factor in the designation of reinforced concrete pavements. The contraction and tensile strength of the concrete are two dependent parameters. Some values are presented as contraction coefficient in terms of the indirect tensile strength of concrete in Table $1[1,3]$.

Table 1. Coefficient of concrete contraction (Hwang, Young, 2004).

\begin{tabular}{cccccc}
\hline $\begin{array}{c}\text { Indirect tensile } \\
\text { strength (MPa) }\end{array}$ & 300 or lower & 400 & 500 & 600 & 700 \\
\hline $\begin{array}{c}\text { Coefficient of } \\
\text { contraction }\end{array}$ & 0.0008 & 0.0006 & 0.00045 & 0.0003 & 0.0002 \\
\hline
\end{tabular}

The aim of this research is to investigate the effect of fibers and cement complements (micro-silica and zeolite) in the promotion of mechanical properties of the cement-based mortars used in repair for overcoming problems resulting from destruction and operation of these mortars in concrete pavements.

\section{Research Background}

\subsection{The Operation of Micro-Silica and Zeolite in the Concrete}

The idea of using a very fine aggregate with a homogeneous and solid composition containing cement materials emerged in early 1980s. This idea was appeared since the researches showed that the weakest area of concrete is the connection of cement paste and aggregate or transition area. The tiny cracks which are created in this area lead to the concrete rupture after development to other areas [4]. The complementary cement materials are produced from the natural and industrial pozzolans which have the ability to amend microstructures of the area of paste transmission, aggregates and reinforced concrete, and improve the concrete durability. The large crystals of calcium hydroxide at the interfacial region between aggregate and paste prevent the increase of strength. Micro-silica is one of the most effective materials of complement cement which causes the production of resistance components called hydrated calcium silicate which causes the improvement of pores size and concentration of the structure in the layer of cement paste and aggregate through the pozzolanic reaction with lime (calcium hydroxide) [5]. This composition is the main factor for increasing strength and decreasing porosity of the constituent particles of concrete. Micro-silica can cause the hydration degree above binder (adhesive material) and is the factor for increasing water 
volume, hydration of cement paste in longer duration of performing pozzolanic reaction and improves the adhesive strength between hardening paste and aggregates in the transition zone [6]. The study results of Ghodoosi et al (2015) on the effect of repair additives on concrete pavements showed that the mortar containing micro-silica and polypropylene and anti-shrinking fibers have better mechanical properties than the mortar with Latex additive [2].

Zeolite is a crystallized mineral with the composition of the hydrated aluminum silicate and alkaline and earth alkaline elements which have an inner network of connected pores that react with the hydrated calcium hydroxide, and its product is the gel of calcium silicate and aluminates in addition to the cement hydration products; as the result, the hardened concrete microstructure is improved particularly in the transmission area of aggregate and cement paste [7,8]. Zeolite causes the decrease of pore size of the cement paste and the replacement of an optimum percentage of it by cement causes the decrease of water absorption and the penetration of chloride ion [9-11]. Zeolite can absorb water 30-40\% of its weight due to two main properties of adsorption and cation exchange, and operates the exchange with more concentration in the vicinity of other cations. These two properties along with the pozzolonic reaction are effective in controlling alkali-silica reactions (ASR) in concrete [9]. The reactivity of zeolite is more than fly ash but lower than silica fume and the reaction with calcium hydroxide and the production of calcium silicate causes the increase of strength [12]. Using zeolite needs a large amount of water compared to fly ash and common concrete because it causes the decrease of slump and efficiency, and this characteristic decreases concrete bleeding and increases adherence and viscosity [10]; moreover, it produces lower hydration heat and decreases dry contraction [13].

\subsection{The Role of Fibers (Polypropylene) in Concrete}

Mineral admixtures like micro-silica increase the concrete fragility [14]. Although the concrete is partly fragile and its fragility increases with the increase of strength, the relatively low tensile strength and the weak strength in opening and extension of cracks are among the main disadvantages of common concrete [15]. Fibers create a continuous composition with the cement concrete and overcome the weaknesses by increasing tensile strength, plasticity, hardness and the improvement of concrete durability properties [16]. This issue pushed the engineers to produce a concrete with high strength and better hardness and durability. This new type includes high strength concrete (HSC), high performance concrete and high performance fibrous reinforced concrete (HPFRC) [17]. Fibers are mainly fabricated by metal, carbon and polymer. Among polymeric fibers, polypropylene fibers have attracted the highest attention because they have low cost, prominent hardness and high strength against the increase of contraction cracks [18].

Polypropylene fibers are not hydrophilic so they do not absorb water and are not destructive. In addition, this category of fibers is resistant against alkaline, chemical materials and chloride and has low heat transfer property. Polypropylene fibers are an appropriate alternative for thermal armature and can control plastic cracks and the cracks resulting from concrete fluctuation and temperature changes appropriately [19, 20].

Abibasheer Basheerudeen studies show that, Concrete mixtures were produced with fibre volume fractions of 0.5 and $0.75 \%$ by volume of concrete. Steel fibre addition reduced the flowability and passing ability but satisfying the suggested limits for SCC. The hardened properties (compression, tension and elastic modulus) were analysed at different ages of concrete (3, 7 and 28 days). At the outset, all the properties were enhanced with age and with the addition of steel fibres. Apart from environmental benefits, M-sand can perform the role of an effective filler material to concrete compared to river sand [21].

\section{Research Methodology}

In the following, we address the chemical characteristics of materials and additives, then the effect of parameters and the most optimal design of mixture based on performing bending, tensile and compressive tests and analysis of results are obtained. 


\subsection{The Characteristics of Used Materials}
a) Cement and cement complements

In this research, the cement type 3 of Shahroud cement factory (Iran) is used as the complementary cement materials. The chemical characteristics of the used materials are shown in Table 2.

Table 2. Chemical characteristics of the used cement, micro-silica and zeolite.

\begin{tabular}{cccccccccc}
\hline Materials & $\mathrm{LOI}$ & $\mathrm{SO}_{3}$ & $\mathrm{~K}_{2} \mathrm{O}$ & $\mathrm{Na}_{2} \mathrm{O}$ & $\mathrm{MgO}$ & $\mathrm{CaO}$ & $\mathrm{Fe}_{2} \mathrm{O}_{3}$ & $\mathrm{Al}_{2} \mathrm{O}_{3}$ & $\mathrm{Si}_{2} \mathrm{O}_{3}$ \\
\hline Micro-silica & 2.6 & 0.1 & 1.056 & 0.556 & 1.61 & 1.87 & 2.12 & 1.2 & 89.2 \\
Zeoite & 10.23 & 0.05 & 1.42 & 2.04 & 1.2 & 1.68 & 1.44 & 13.66 & 67.79 \\
Cement type 3 & 2.4 & 2.58 & 0.56 & 0.24 & 1.54 & 62.89 & 3.73 & 3.9 & 20.87 \\
\hline
\end{tabular}

b) Fibers

The used fibers in this research are polypropylene with $12 \mathrm{~mm}$ length which their physical characteristics are shown in Table 3.

Table 3. Physical properties of polypropylene fibers.

\begin{tabular}{cccccc}
\hline $\begin{array}{c}\text { Water } \\
\text { absorption }\end{array}$ & $\begin{array}{c}\text { Length } \\
(\mathrm{mm})\end{array}$ & $\begin{array}{c}\text { Diameter } \\
(\mu \mathrm{m})\end{array}$ & $\begin{array}{c}\text { Bulk density } \\
\left(\frac{\mathrm{g}}{\mathrm{cm}^{3}}\right)\end{array}$ & $\begin{array}{c}\text { Tensile strength } \\
(\mathrm{MPa})\end{array}$ & $\begin{array}{c}\text { Melting point } \\
\left({ }^{\circ} \mathrm{C}\right)\end{array}$ \\
\hline $\mathrm{No}$ & 12 & 22 & 0.91 & $350-400$ & $160-170$ \\
\hline
\end{tabular}

c) Aggregate

The used sand was prepared from the resources of Semnan province. The sand was completely mixed and then separated to four parts in order to select the sample for performing granularity test and we equally took the sand from each part. Total mass of the sample is 1000gr. The used sand granularity is shown in Fig. 1.

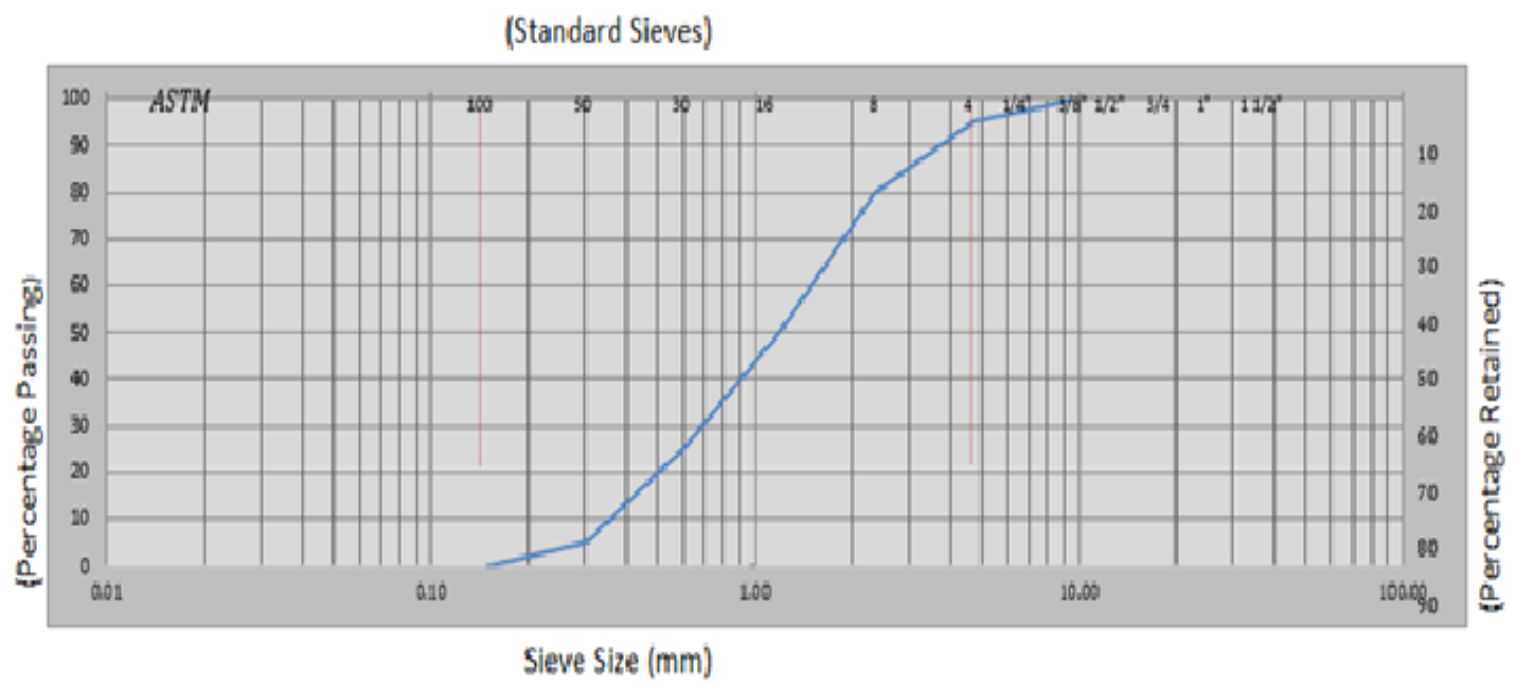

Fig. 1. Curve of the used sand granularity in mixing designs. 
d) Water and super lubricant

Tap water of the laboratory of Semnan University has been used for fabricating the samples. The chemical properties of the used super lubricants are shown in Table 4.

Table 4. The characteristics of the used super lubricants.

\begin{tabular}{ccccc}
\hline Physical state & Color & Basis & Chloride ion & Bulk density \\
\hline \multirow{2}{*}{ Liquid } & Clouded yellow & Polycarboxylic ether & No & $1.1 \frac{\mathrm{g}}{\mathrm{cm}^{3}}$ \\
\hline
\end{tabular}

\subsection{Mixture Design}

In this paper, optimum percentages of other researches were used in three states of control sample, samples containing fibers and samples containing combined fiber and cement complements. Polypropylene with the length of $12 \mathrm{~mm}$ with two values of 0.2 and $0.4 \%$ wt of cement and cement complements with the values of 5 and $10 \%$ micro-silica and 7.5 and $15 \%$ zeolite as $\mathrm{wt} \%$ of the used cement were utilized. A part of cement was replaced by cement complements in the mixture. In this research, 11 mixture designs were prepared by the description in Table 5 and were used. The samples were casted in stirring apparatus inside molds after fabrication. Figure 2 shows some stages of doing the work.

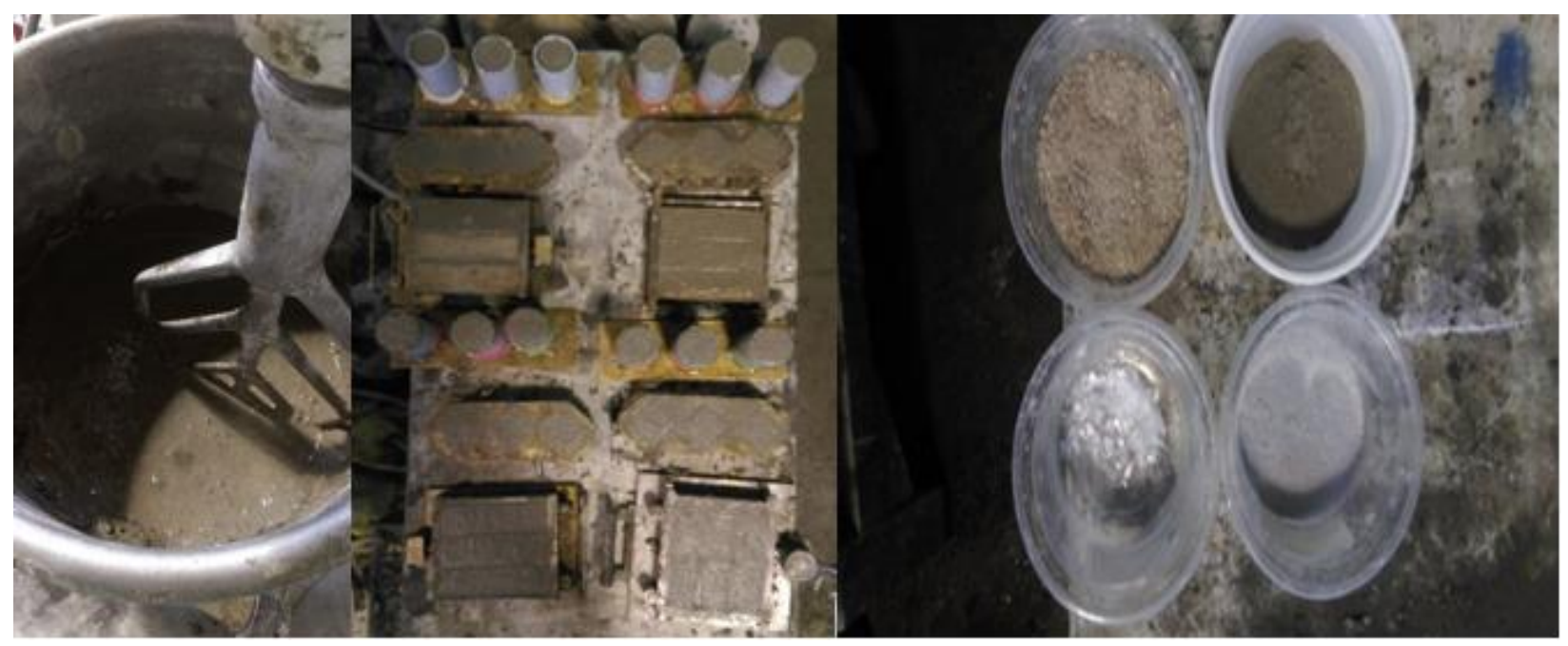

Fig. 2. The used materials, the samples casted in the molds and the method of mixing the materials.

Table 5. The used mixing designs.

\begin{tabular}{cccccccc}
\hline $\begin{array}{c}\text { Mixing } \\
\text { design no. }\end{array}$ & Abbreviation & $\begin{array}{c}\text { Cement } \\
(\mathrm{gr})\end{array}$ & $\begin{array}{c}\text { Polypropylene } \\
\text { fibers (PP/B) }\end{array}$ & $\begin{array}{c}\text { Micro- } \\
\text { silica and } \\
\text { zeolite } \\
(\mathrm{SF}, \\
\mathrm{Ze} / \mathrm{B})\end{array}$ & $\begin{array}{c}\text { Sand } \\
(\mathrm{S} / \mathrm{B})\end{array}$ & $\begin{array}{c}\text { Water } \\
(\mathrm{W} / \mathrm{B})\end{array}$ & $\begin{array}{c}\text { Super } \\
\text { lubricant } \\
\text { (SP/B) }\end{array}$ \\
\hline$C_{1}$ & $S h$ & 400 & 0 & 0 & 2.7 & 0.4 & 0.02 \\
$C_{2}$ & $P_{2}$ & 400 & 0.02 & 0 & 2.7 & 0.4 & 0.02 \\
$C_{3}$ & $P_{4}$ & 400 & 0.04 & 0 & 2.7 & 0.4 & 0.02 \\
$C_{4}$ & $P_{2} S F_{5}$ & 380 & 0.02 & 0.05 & 2.7 & 0.4 & 0.02 \\
$C_{5}$ & $P_{2} S F_{10}$ & 360 & 0.02 & 0.1 & 2.7 & 0.4 & 0.02
\end{tabular}




\begin{tabular}{cccccccc}
\hline $\begin{array}{c}\text { Mixing } \\
\text { design no. }\end{array}$ & Abbreviation & $\begin{array}{c}\text { Cement } \\
(\mathrm{gr})\end{array}$ & $\begin{array}{c}\text { Polypropylene } \\
\text { fibers (PP/B) }\end{array}$ & $\begin{array}{c}\text { Micro- } \\
\text { silica and } \\
\text { zeolite } \\
(\mathrm{SF}, \\
\mathrm{Ze} / \mathrm{B})\end{array}$ & $\begin{array}{c}\text { Sand } \\
(\mathrm{S} / \mathrm{B})\end{array}$ & $\begin{array}{c}\text { Water } \\
(\mathrm{W} / \mathrm{B})\end{array}$ & $\begin{array}{c}\text { Super } \\
\text { lubricant } \\
(\mathrm{SP} / \mathrm{B})\end{array}$ \\
\hline$C_{6}$ & $P_{4} S F_{5}$ & 380 & 0.04 & 0.05 & 2.7 & 0.4 & 0.02 \\
$C_{7}$ & $P_{4} S F_{10}$ & 360 & 0.04 & 0.1 & 2.7 & 0.4 & 0.02 \\
$C_{8}$ & $P_{2} Z_{7.5}$ & 370 & 0.02 & 0.075 & 2.7 & 0.4 & 0.02 \\
$C_{9}$ & $P_{2} Z_{15}$ & 370 & 0.02 & 0.15 & 2.7 & 0.4 & 0.02 \\
$C_{10}$ & $P_{4} Z_{7.5}$ & 340 & 0.04 & 0.075 & 2.7 & 0.4 & 0.02 \\
$C_{11}$ & $P_{4} Z_{15}$ & 340 & 0.04 & 0.15 & 2.7 & 0.4 & 0.02 \\
\hline
\end{tabular}

\subsection{The Performed Experiments}
a) Test of mortar compressive strength

According to ASTM C 109 Standard, cubic samples with the dimensions of $50 \times 50 \times 50 \mathrm{~mm}$ were used for compressive strength test. The samples were casted in the intended molds after mixing and were crushed in two layers with the specific pounder and were loaded by the specific jack after 28 days processing in water. Figure 3 shows the apparatus for measuring the compressive strength [22].

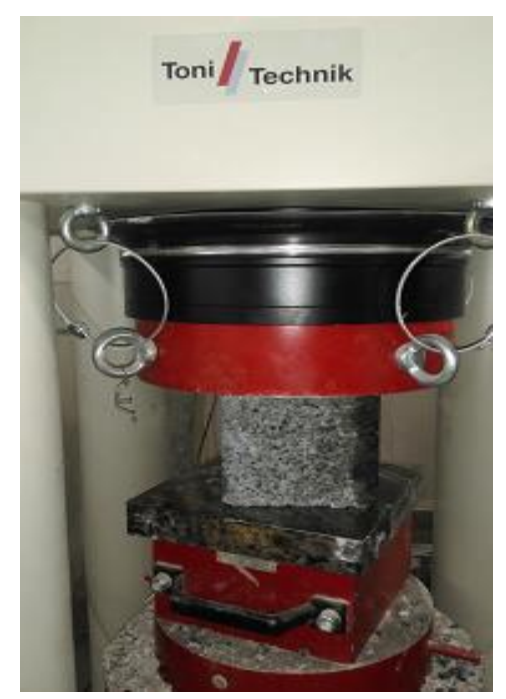

Fig. 3. Apparatus of measuring compressive strength.

b) Test of mortar bending strength

According to ASTM C 348 Standard, cubic samples with the dimensions of $40 \times 40 \times 160 \mathrm{~mm}$ must be used for testing bending strength. The samples were casted in the intended mold after mixing, were crushed in two layers with the specific pounder and were loaded by the specific jack after 28 days processing in water. Figure 4 shows the apparatus for measuring the bending strength [23]. 


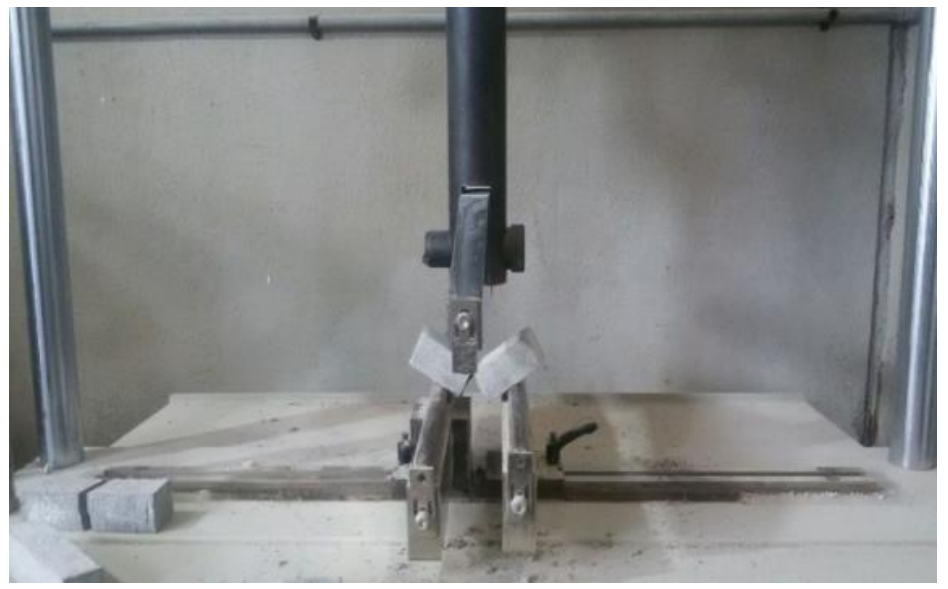

Fig. 4. The apparatus for measuring the bending strength of samples with the universal apparatus.

c) Test of tensile strength by indirect method

According to ASTM C 496 Standard, cylindrical samples with the diameter to height ratio of 0.5 are used and the diameter of the samples is considered $55 \mathrm{~mm}$. This test is known as the indirect tensile test (Brazilian method). For doing this test, the sample of cylindrical mortar is located horizontally beneath jack and inside the specific apparatus of this test and the force of jack is inserted uniformly and linearly to the cylindrical sample by solid rod above the sample. Figure 5 shows the loaded samples by apparatus [24].

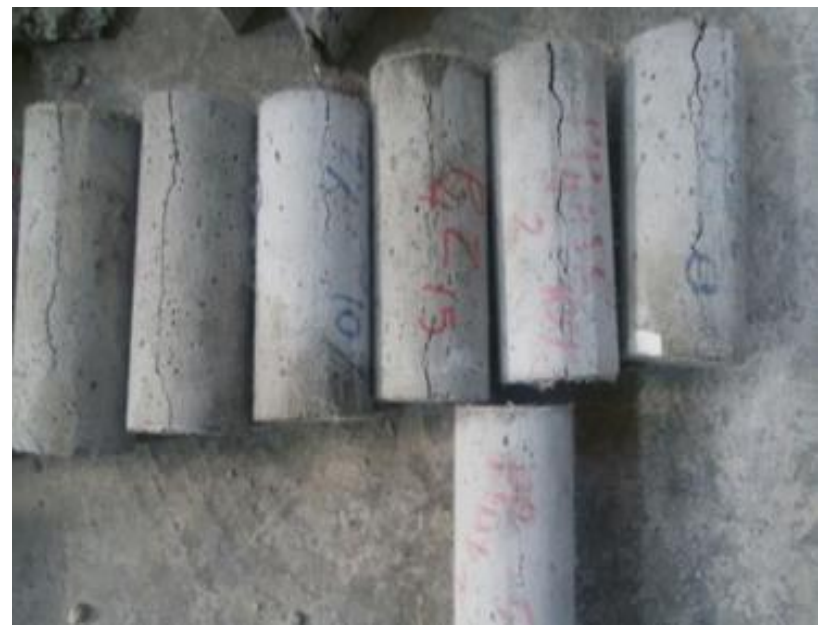

Fig. 5. The loaded cylindrical samples.

\section{Analysis of Experimental Results}

\subsection{Compressive Strength}

The compressive strength of concrete is increased by adding fibers and this value is increased by increasing the $\mathrm{wt}^{\%} \%$ of fibers to $0.4 \%$. However, from $0.2 \%$ to $0.4 \%$, the compressive strength is increased with lower slope which testifies that the fibers can result in decreasing the strength in higher percentages. Using microsilica and Zeolite causes the increase of compressive strength, and this increase account for the decrease of instability in calcium hydroxide and the increase of adherence and continuity of cement and aggregates.

With regard to the used values of micro-silica and zeolite, it can be said that the effect of micro-silica is more than zeolite and this issue is due to more reactivity in micro-silica. However, the effect of additional aluminates cannot be ignored in the process of producing calcium silicate gel in zeolite operation. The highest compressive strength was observed in the samples containing 10\% micro-silica and 15\% zeolite with $0.4 \%$ fibers which is due to the combined effects of fibers with pozzolans and the increase of fibers 
adherence with mortar paste by the help of pozzolonic operation of micro-silica and zeolite. Figures 6,7 , and 8 show the compressive strength of the samples.

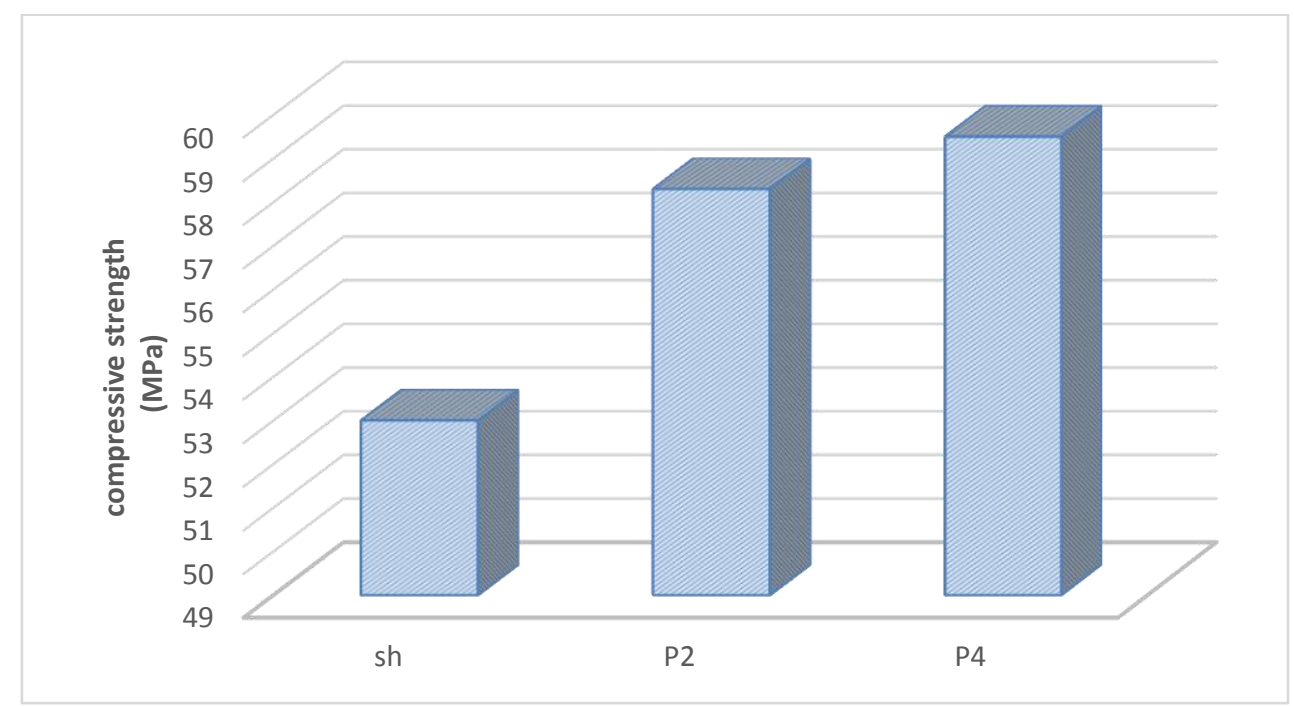

Fig. 6. The effect of fibers on compressive strength.

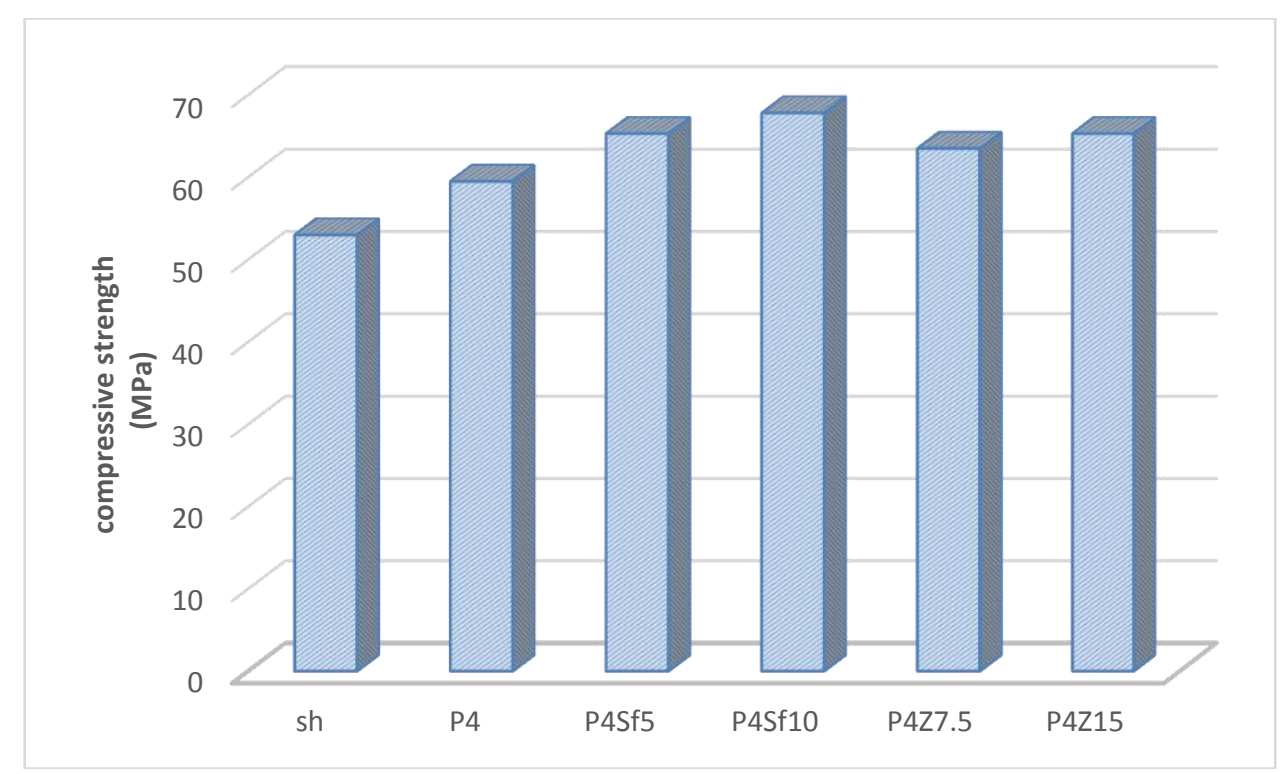

Fig. 7. The effect of zeolite on compressive strength of the samples containing fibers. 


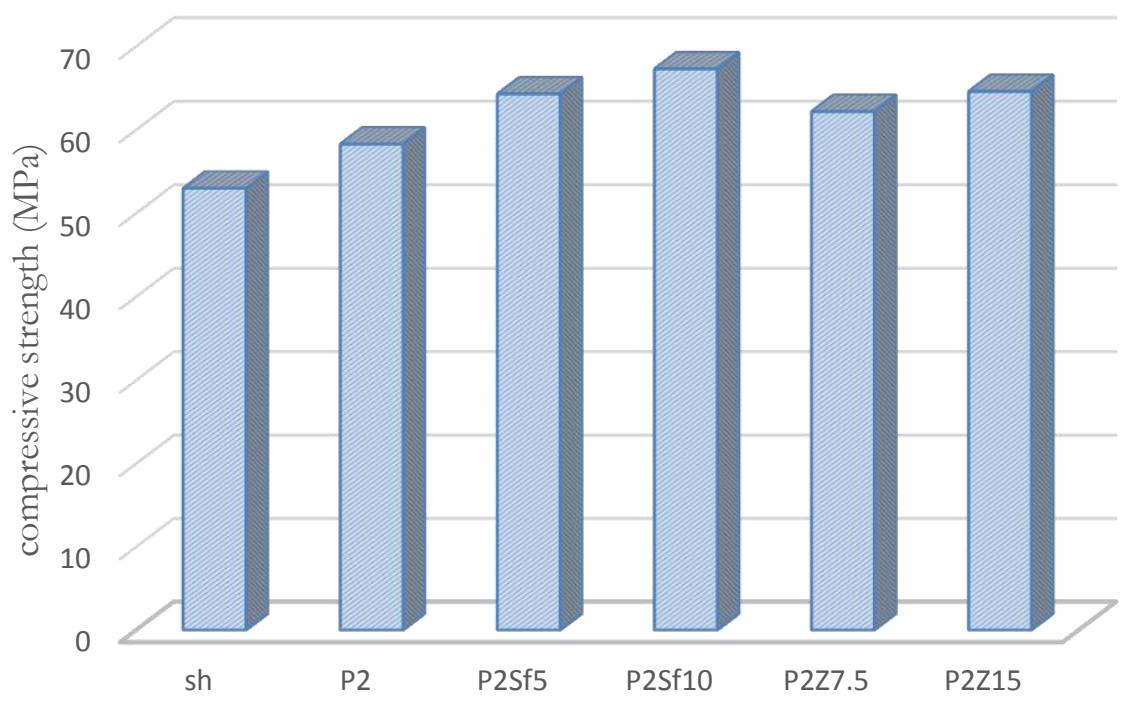

Fig. 8. The effect of micro-silica on compressive strength of the sample containing fibers.

\subsection{Tensile Strength}

The tensile strength of fibrous concrete samples shows an increase relative to the control sample and the increase rate is reduced by increasing the fibers $w t \%$ from 0.2 to 0.4 . But the highest rate of the increase in tensile strength has been observed in the concrete samples containing $0.4 \%$ of fibers. Adding micro-silica and zeolite together with fibers partly increases tensile strength, while micro-silica affects greater than zeolite.

The considerable feature in the tensile strength with Brazilian method (bisecting) by adding polypropylene fibers is that the samples are not completely ruptured in the tension with primary strength they show, and/or they show individual characteristics in the samples containing $0.4 \%$ fibers by deformation from spherical state to elliptical state by splay value in rupture surface. This operation of fibrous mortars in patch repairs causes concrete pavements containing cement mortars to be less fractured and ruptured under the stresses of inserted traffic loads and thermal stresses. Figures 9, 10, and 11 show the tensile strength of the samples.

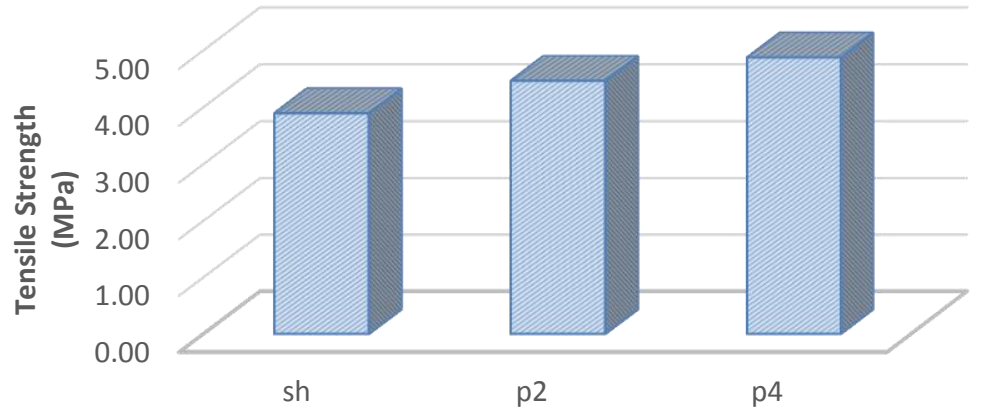

Fig. 9. The effect of fibers on tensile strength. 


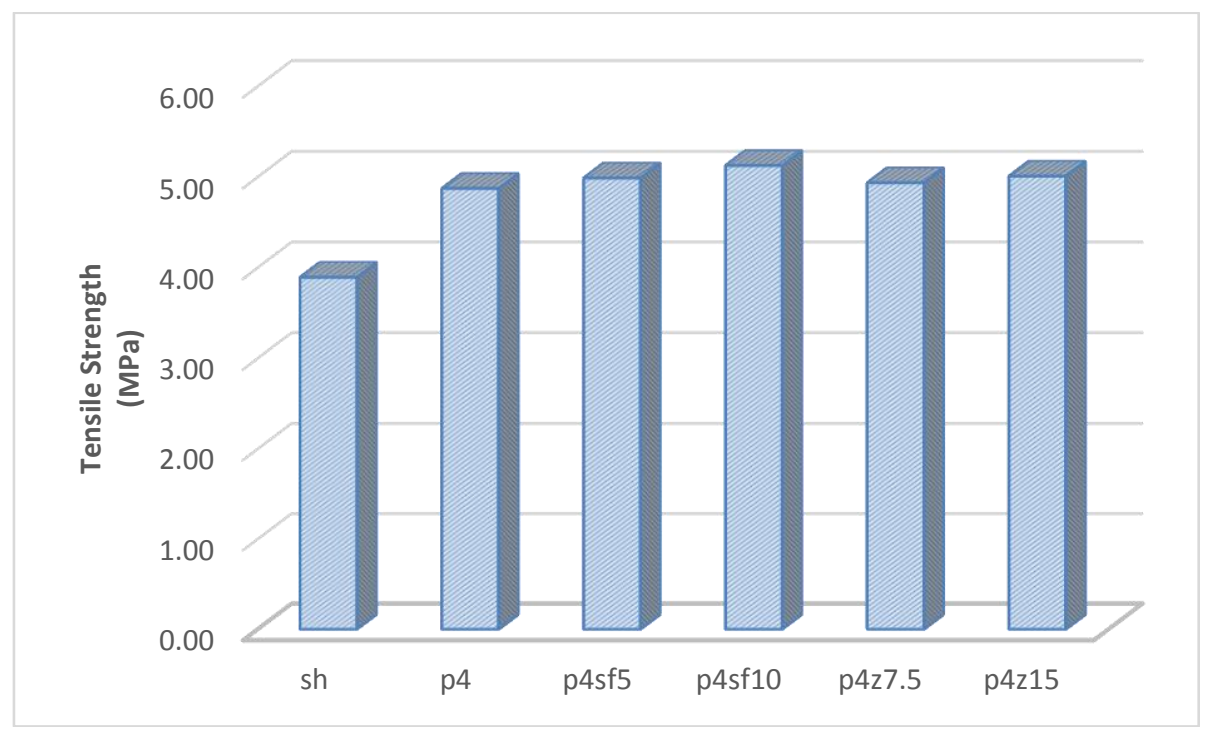

Fig. 10. The effect of zeolite on tensile strength of the samples containing fibers.

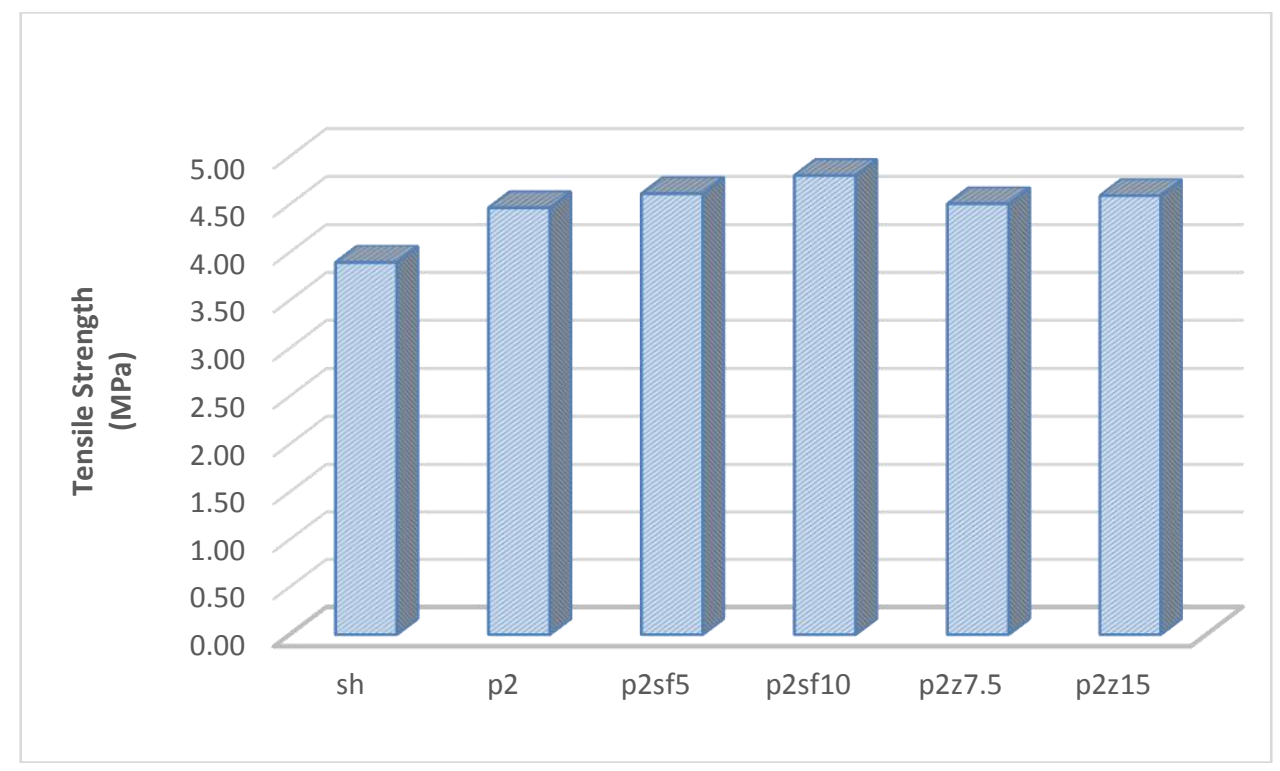

Fig. 11. The effect of micro-silica on tensile strength of the samples containing fibers.

\subsection{Bending Strength}

Bending strength of the fibrous samples is increased by increasing fiber percentage, while this increase is not considerable by adding micro-silica and zeolite. But the adherence and continuity of mortar partly causes the increase of bending strength affected by the pozzolonic reaction and the production of calcium silicate gel.

The considerable result is the similar operation of the samples containing $10 \%$ micro-silica and $15 \%$ zeolite containing 0.2 and $0.4 \%$ fibers to the samples containing $5 \%$ micro-silica and $7.5 \%$ zeolite with the same percent of fibers in bending which its reason is because of the increase in stiffness and fragility of mortar by increasing the percentage of cement complements. Figures 12, 13, and 14 show the bending strength of the samples. 


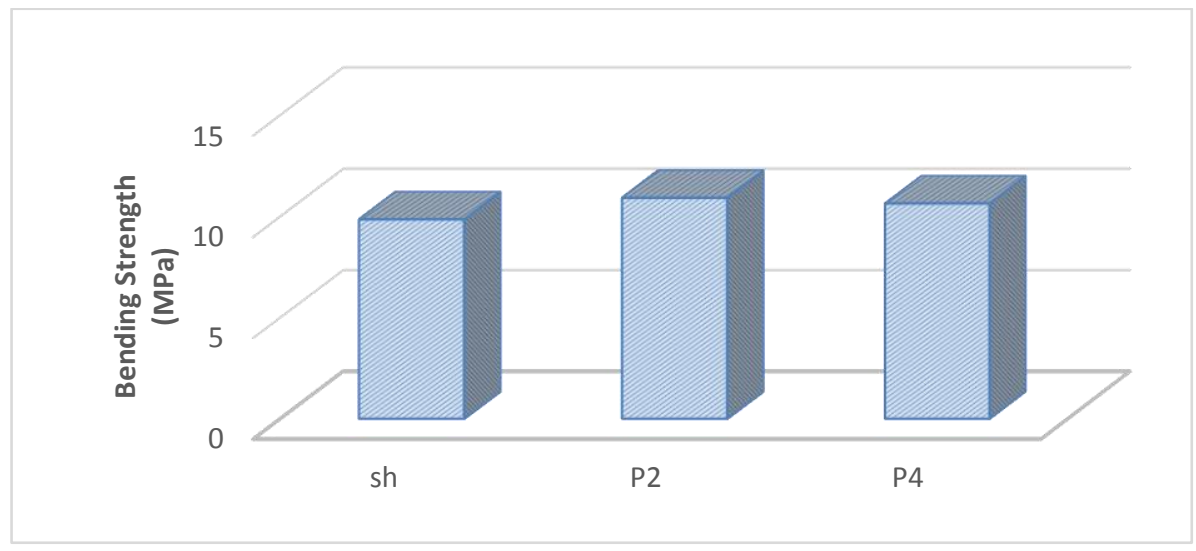

Fig. 12. The effect of fibers on bending strength.

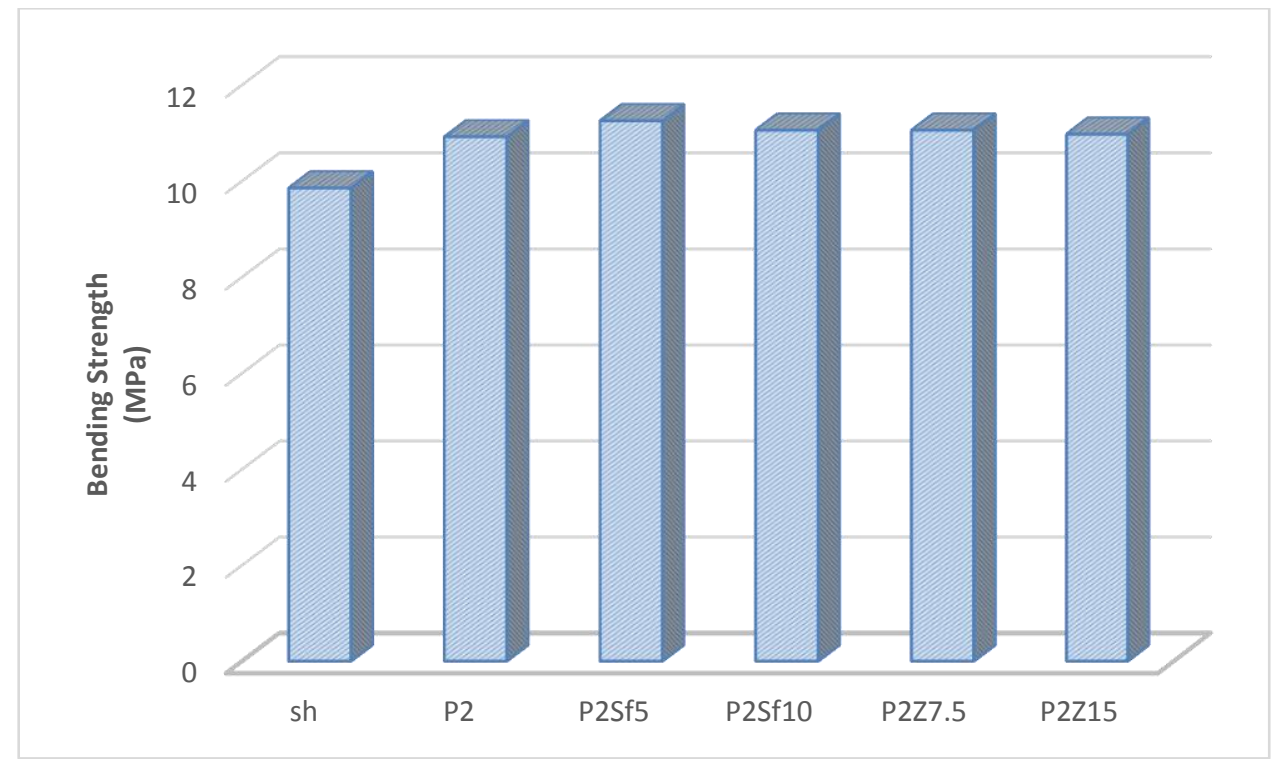

Fig. 13. The effect of zeolite on bending strength of the samples containing fibers.

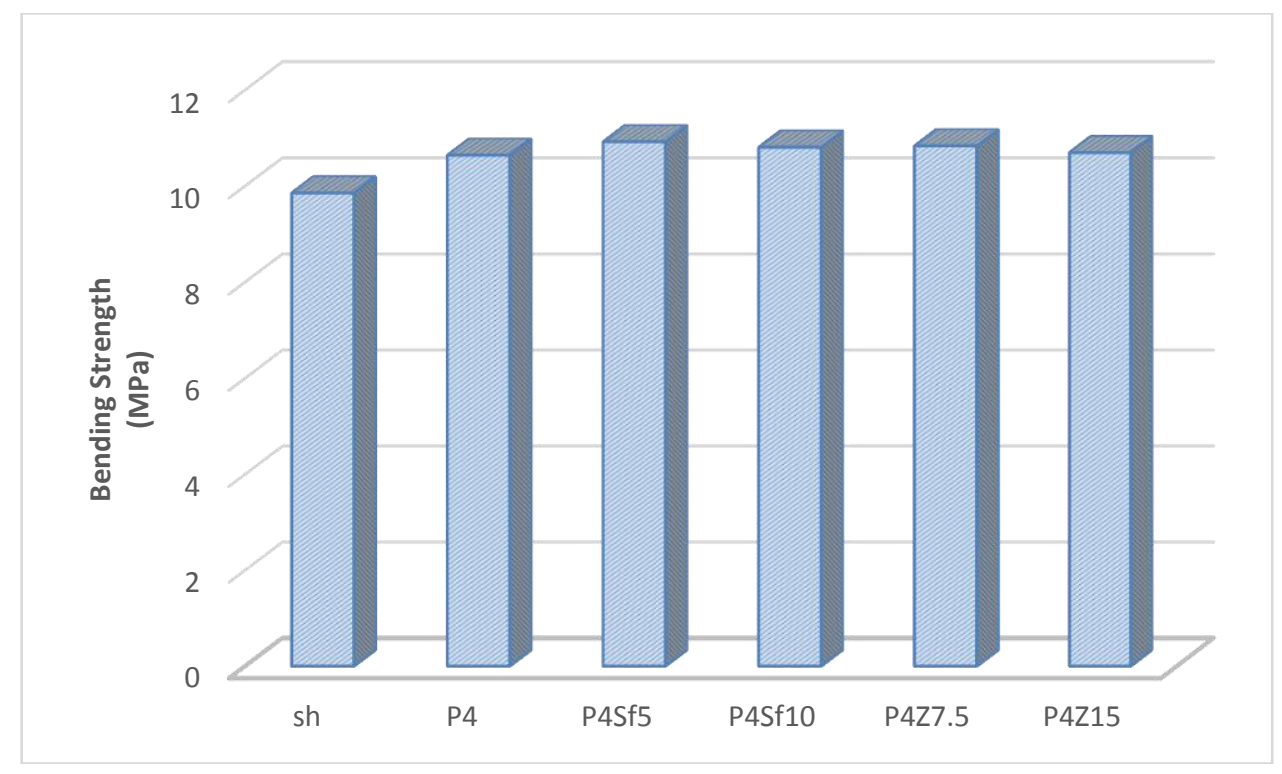

Fig. 14. The effect of micro-silica on bending strength of the samples containing fibers. 


\section{Conclusion}

- The optimum percentage of polypropylene fibers with micro-scale thickness promotes the compressive strength of cement-based repair mortars, but the increase or decrease of fiber percent can have different operation; also the combination of fibers with cement complements causes the considerable increase of compressive strength and the increase of elasticity modulus in pavement repair mortar.

- By adding polypropylene fibers, the samples are not ruptured completely in the tension with primary strength they show and/or the samples containing $0.4 \%$ fibers with deformation from spherical state to elliptical state with splay value in the rupture surface show individual characteristic. This performance of the fibrous mortars cause to minimize fraction and rupture in concrete pavements with cement mortars under the stresses due to the inserted traffic loads and thermal stresses.

- The combination of fibers and cement complements causes the increase of tensile strength and the decrease of contraction in cement-based mortars in the repair of concrete pavements.

- Fibers cause the increase of bending strength, but by increasing the percentage of cement complements in bending strength, no special change is obtained; this is because of the increase in stiffness and fragility of mortar with increasing the percent of cement complements.

- The combined role of fibers and cement complements can considered in $0.2 \%$ fibers with $10 \%$ microsilica and $15 \%$ zeolite as the optimum design of mixing in order to promote the effective parameters of elasticity modulus, rupture modulus and contraction decrease in the repair mortars of concrete pavements.

- With regard to the appropriate operation of adding zeolite and polyprolylene fibers, the abundance of this mineral crystal in Semnan province (Iran) and its low cost, it can be used in the repair and preservation of concrete pavements.

\section{References}

[1] A. Hasani, Concrete Pavement of Roads-Design, Implementation and Preservation. Mashhad: Transportation Institute, Imam Reza University, 2013.

[2] P. Ghodoosi, J. Shirzadi, P. Hayati and A. Salehi, "The properties of the mortars containing repair additives for reforming concrete pavements," in First National Conference of Concrete Pavements, Tarbiat Modares University, Tehran, Iran, 2015.

[3] Y. Huang, Pavement Analysis and Design. Prentice Hall, 2004.

[4] P. Mahta and P. Monteiro, Microstructure, Properties and Components Of Concrete (Advanced Concrete Technology). Business, Technology, 1930.

[5] S. Diamond and S. Sahu, "Densified silica fume particle sizes and dispersion in concrete," Mater. Struct., vol. 39, no. 9, p. 849-859, 2006.

[6] Z. Zhang, B. Zhang and P. Yan, "Comparative study of effect of raw and densified silica fume in the paste, mortar and concrete," Construction and Building Materials, vol. 105, pp. 82-93, 2015.

[7] C. Poon, L. Lam, S. Kou and Z. Lin, "A study on the hydration rate of natural zeolite blended cement pastes," Construction and Building Materials, vol. 13, no. 8, pp. 427-432, 1999.

[8] T. Perraki, G. Kakali and F. Kontoleon, "The Effect of natural zeolites on the early hydration of Portland cement," Microporous and Mesoporous Materials, vol. 61, no. 1-3, pp. 205-212, 2003.

[9] B. Ahmadi and M. Shekarchi, "Use of natural zeolite as a supplementary cementitious material," Cement \& Concrete Composites, vol. 32, p. 134-141, 2010.

[10] H. Eskandaria, M. Vaghefib and K. Kowsaric, "Investigation of Mechanical and Durability Properties of Concrete Influenced by Hybrid Nano Silica and Micro Zeolite," in 5 th International Biennial Conference on Ultrafine Grained and Nanostructured Materials, UFGNSM15, Tehran, Iran, 2015.

[11] M. Valipour, F. Pargar, M. Shekarchi and S. Khani, "Comparing a natural pozzolan, zeolite, to metakaolin and silica fume in terms of their effect on the durability characteristics of concrete," Construction and Building Materials, vol. 41, p. 879-888, 2013.

[12] Y. Kocak, E. Tasc and U. Kaya, "The effect of using natural zeolite on the properties and hydration characteristics of blended cements," Construction and Building Materials, vol. 47, pp. 720-727, 2013.

[13] C.-S. Shon and Y.-S. Kim, "Evaluation of West Texas natural zeolite as an alternative of ASTM Class F fly ash," Construction and Building Materials, vol. 47, p. 389-396, 2013. 
[14] M. Nili and V. Afroughsabet, "Combined effect of silica fume and steel fibers on the impact resistance and mechanical properties of concrete," Int. J. Impact Eng, vol. 37, no. 8, p. 879-886, 2010.

[15] K. Kuder and S. Shah, "Processing of high-performance fiber-reinforced cement based composites," Constr. Build. Mater., vol. 24, no. 2, p. 181-186, 2010.

[16] A. Ezeldin and P. Balaguru, "Bond behaviour of normal and high strength fiber reinforced concrete," ACI Mater. J., vol. 86, no. 5, p. 515-524, 1989.

[17] J. Lim and T. Ozbakkaloglu, "Influence of silica fume on stress-strain behavior of FRP-confined HSC," Constr. Build. Mater, vol. 63, p. 11-24, 2014.

[18] P. Zhang and Q.-F. Li, "Effect of polypropylene fiber on durability of concrete composite containing fly ash and silica fume," Composites Part B: Engineering, vol. 45, no. 1, p. 1587-1594, 2013.

[19] N. Banthia and R. Gupta, "Influence of polypropylene fiber geometry on plastic shrinkage cracking in concrete," Cem. Concr. Res., vol. 36, no. 7, p. 1263-1267, 2006.

[20] M. Keyhani, "Investigation of the effect of polypropylene fibers on the properties of fresh and hardened concrete," in Fifth Annual National Conference of Concrete, Tehran, Iran, 2013.

[21] A. Basheerudeen and S. Anandan, "Simplified mix design procedures for steel fibre reinforced self compacting concrete," Engineering Journal, vol. 19, no. 1, p. 21-36, 2015.

[22] Standard Test Method for Compressive Strength of Hydraulic Cement Mortars (Using 2-in. or [50-mm] Cube Specimens), ASTM C 109 - 07.

[23] Standard Test Method for Flexural Strength of Hydraulic-Cement Mortars, ASTM C 348 - 02.

[24] Standard Test Method for Splitting Tensile Strength of Cylindrical Concrete Specimens, ASTM C 496 - 04. 